\title{
Linear and Non-Linear Static Analysis of Berthing Structure
}

\author{
K. Naga Sri Lakshmi ${ }^{1}$ I S Naveen Kumar ${ }^{2}$
}

1PG Scholar, Department of Civil Engineering, Visakha Technical Campus, Andhra Pradesh, India.

${ }^{2}$ Assistant Professor, Department of Civil Engineering, Visakha Technical Campus, Andhra Pradesh, India.

\section{To Cite this Article}

K. Naga Sri Lakshmi and S Naveen Kumar, "Linear and Non-Linear Static Analysis of Berthing Structure", International Journal for Modern Trends in Science and Technology, 6(9): 13-18, 2020.

\section{Article Info}

Received on 06-August-2020, Revised on 20-August-2020, Accepted on 25-August-2020, Published on 28-August-2020.

\section{ABSTRACT}

Rapid growth in the water transport system demands the construction of more port and harbour structures.Berthing structures are constructed in ports and harbours to provide facilities such as berthing and mooring of vessels, loading and unloading of cargo and embarking and disembarking of passengers. Quays, wharfs, piers, jetties and dolphins are the most widely used berthing structures. In this project, linear and non-linear static analysis berthing structure module is studied. The basic data influence factors which affected the berthing structure were taken into consideration, such as soil characteristics of the proposed location, environmental conditions and range of traffic which will be used in the project is generally taken from Visakhapatnam port. The entire Berth length is $506.4 \mathrm{~m}$ which is divided into 10 modules and each module length is $50.640 \mathrm{~m}$ and width of the berth is $33.450 \mathrm{~m}$. The Berth has been analyzed by using STAAD Pro Software. After performing the linear and non-linear static analysis of the berthing structure module the behaviour of the structural elements is compared by various parameters deflection, bending moments, shear forces of cross beam, long beam, crane beam, front crane beam, retaining beam and also for the different piles. The axial forces variations of different piles are also studied.

KEYWORDS: Berthing Structure, STAAD Pro, Linear and Non-Linear Static analysis.

\section{INTRODUCTION}

Quick development in the water transport framework requests the development of more port and harbor structures. The old civic establishments had extraordinary, instinctive information on their oceanic offices, which lamentably got lost with the decrease of realms and the changing of the beaches. Wood and stone ports and harbors constructed short of what 100 years prior are continuously being supplanted by cement and steel structures, which has expanded oceanic port offices into more profound waters and uncovered areas. All things considered, port and dock fashioners still depend intensely on the investigation of past encounters to consummate their examination and practice of contemporary tasks. And furthermore, ports are one of the most significant key purposes of a nation's economy, since a lot of its large-scale manufacturing is typically dispatched through them. Sea offices are the indispensable association between land, street, or rail transport and the streams, and it is essential that boats and vessels be stacked and emptied rapidly and proficiently at these locales.

Berthing structures are developed in ports and harbors to give offices, for example, berthing and securing of vessels, stacking and emptying of payload and leaving and landing of travelers. Quays, wharfs, docks, piers and dolphins are the most generally utilized berthing structures. 
Analysis and Design of berthing structures seem to be a new subject to common structural engineers, but they are the important structures contributing to the development of trade in our nation.The Earthquakes have caused severe damage to such structures in the past and these risks should be eliminated at any cause.In this project, comparison of linear and non-linear static analysis berthing structure module is studied

\section{Touch Pile:}

The generally utilized impermanent or lasting holding divider for unearthing in urban zones are called Touch piles. If there should arise an occurrence of over solidified muds, soils over the water table have some union, and free depleting soils which can be viably dewatered, similar to sands, the touch heaps can be appropriate. Contact heaps comprise of products heaps dispersed separated from one another to help a difference in height. Contingent upon the state of Touch pile Shoring, the size of the heaps and the dividing between them can be acclimated to site soil conditions.

\section{Types of touch piles:}

1. Secant pile wall

2. Tangent pile wall

\section{Tangent Pile Wall:}

From the secant pile walls and soldier pile walls the tangent pile walls are different. There is no overlap and ideally one pile touches the other. following advantages tangent pile walls -

- Increased construction alignment flexibility.

- Construction is Easier and quicker.

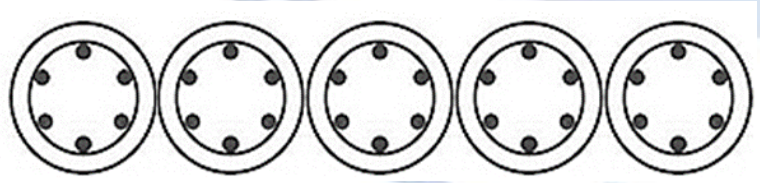

Figure-1: Tangent Piles

\section{Objective of The Present Study:}

Following particular objectives are decided for the existing study:

1.To Analysis of berthing structure as per guidelines provided by the bureau of Indian Standards.

2.To know how to model and analyzing of berthing structure by using STAAD PRO.

3. To study the behavior of berthing structure during equivalent static analysis by using STAAD Pro Software.

4. To study the behavior of berthing structure during pushover analysis by using STAAD Pro Software.

5.To compare the linear and nonlinear static analysis results of the berthing structure.

\section{II.LITERATURE REVIEW}

The study of previous studies gives a summary of the researches accomplished endeavorsto know the structural behaviour of the berthing structures for various loads acting on it. And they used various software to evaluate the behaviour of the berthing structure.

\section{Kinjal Patel:}

The Analysis and Design of Marine Berthing Structure suggest the Structural components are physically planned by utilizing limit state structure and the entire Berthing structure investigation is finished by utilizing STAAD Pro Software. According to restrict state plan the Design of Slab, Beam has been finished. The most extreme positive and greatest negative twisting snapshot of the shaft is taken from the manual investigation report and planned by utilizing the breaking point state strategy for structure. The shear fortification is given and the pressure and strain support is determined. In this examination the auxiliary components in the berthing structure are planned and fortification subtleties are determined effectively.

\section{B. Santosh Kumar:}

In the task depicted an appropriate method to plan another berthing structure with case of one of the proposed berthing structure in Visakhapatnam port. In this way, the components which affected on the structure were thought about of before dissecting and planning, the impact, for example, soil qualities of the proposed area, ecological conditions and scope of traffic.

All the essential Data is taken from Visakhapatnam port which should be utilized in the task, for example, geotechnical information, natural information, and traffic anticipating information. The whole length of compartment is $100 \mathrm{~m}$ and is isolated into 3 units of each 33.33 long with a development joint of $40 \mathrm{~mm}$ between 
progressive units and proposed in the inward harbor, implied for taking care of fluid payload like Sulphuric corrosive, Phosphoric corrosive, phosphoric corrosive, consumable oils and so on.

\section{S. Nagarjuna:}

In the current examination, a proposed berthing structure EQ-10 is taken for investigation and plan. All appropriate information is gathered from Visakhapatnam port trust and their site like geotechnical information, ecological information, and traffic estimating information. By utilizing all this information, we arranged and displayed a structure. After that we determined different burdens prompted on structure and we broke down the displayed structure in STAAD-PRO because of the regular burden appropriation on structure. In reality we have followed with various measurements for most worthy structure, in that following we reasoned that bigger width heap gets less avoidance when contrast and littler breadth heaps. At long last the structure was dissected and planned with opposing of marine conditions and fulfilling in the part of efficient and wellbeing.

The whole EQ (Eastern Quay)- 10 billet length of $100.07 \mathrm{~m}$ is partitioned into 3 units of each 33.33 long with a development joint of $40 \mathrm{~mm}$ between progressive units. The proposed EQ-10 billet at Visakhapatnam Port in the inward harbor is intended for dealing with fluid payload like Sulphuric corrosive, Phosphoric corrosive, phosphoric corrosive, palatable oils and so forth.

\section{Augustina S:}

This task is concentrating on investigation and plan of second traveler compartment at Beypore port, Kozhikode. It's an open heaped exhausted cast-insitu structure and lying in the seismic zone III. The billet is to be intended for a vessel having limit of 5000DWT. The structure is exposed to different powers and mixes, for example, High tide, Earthquake, High breezes, overwhelming live loads according to May be: 4651-1983. A model was created utilizing STAAD Pro programming and examination was led with suitable burdens following up on the structure. It was seen that seismic power was ostensible since Beypore being situated in seismic zone III. This exploration is an endeavor to comprehend the idea of plan and investigation of berthing structures under various states of stacking.

\section{Anjana S Rao:}

In this examination Berthing structures are exposed to sidelong powers brought about by effect of berthing ships, pull from securing ropes, weight of wind, waves and skimming ice, seismic power, dynamic earth pressure, differential water pressure and live burden on the structure. The berthing structure must be dissected and planned appropriately, so as to evade the disappointment because of these heaps. The investigation should be possible utilizing different programming, for example, STAAD.Pro, PLAXIS, ANSYS, StruCAD 3D and so on. It is discovered that the variety of twisting second and uprooting is more in powerful investigation than in static examination. Dynamic examination is more basic and ought to be considered during the plan of the structure.

\section{G. T. Naidu:}

This examination points the conduct of berthing structure by utilizing Reliability based investigation when exposed to variable crane burden and furthermore to decide the part attributes of each auxiliary segment. For displaying of structure, the STAAD Pro and MATLAB programming's are utilized for Reliability examination.

\section{METHDOLOGY}

In this project, linear and non-linear static analysis berthing structure module is studied. The basic data will be used in the project is generally taken from Visakhapatnam port. The entire Berth length of $50.640 \mathrm{~m}$ and width of the berth is $33.450 \mathrm{~m}$. The Berth has been analyzed by using STAAD Pro Software.

Step by step process of present study:

- Study of Previous Studies

- Geometry of The Structure

- Loads and Load Combinations

- Modeling of The Structure

- Linear and Non-Linear static Analysis of Berthing Structure by Using STTAD Pro

\section{ANALYSIS OF BERTHING STRUCTURE BY USING STAADPRO}

Table-1:Primary Data for Berthing Structure

\begin{tabular}{|l|l|}
\hline Length of The Berthing & $560 \mathrm{~m}$ \\
\hline Width of The Berthing & 33.45 \\
\hline Number of Modules $=$ & 11 \\
\hline
\end{tabular}




\begin{tabular}{|l|l|}
\hline Module Dimensions = & $50.6 \times 33.45$ \\
\hline Draft $=$ & $28 \mathrm{~m}$ \\
\hline DWT $=$ & 80,000 \\
\hline Seismic Zone $=$ & $\mathrm{II}$ \\
\hline Response Reduction Factor $=$ & 3 \\
\hline Importance Factor & 1.5 \\
\hline Soil Type $=$ & $\mathrm{II}$ \\
\hline Front Carne Beam $=$ & $1900 \times 3000$ \\
\hline Crane Beams $=$ & $1500 \times 1700$ \\
\hline Long Beams $=$ & $800 \times 1200$ \\
\hline Cross Beams $=$ & $1600 \times 1800$ \\
\hline
\end{tabular}

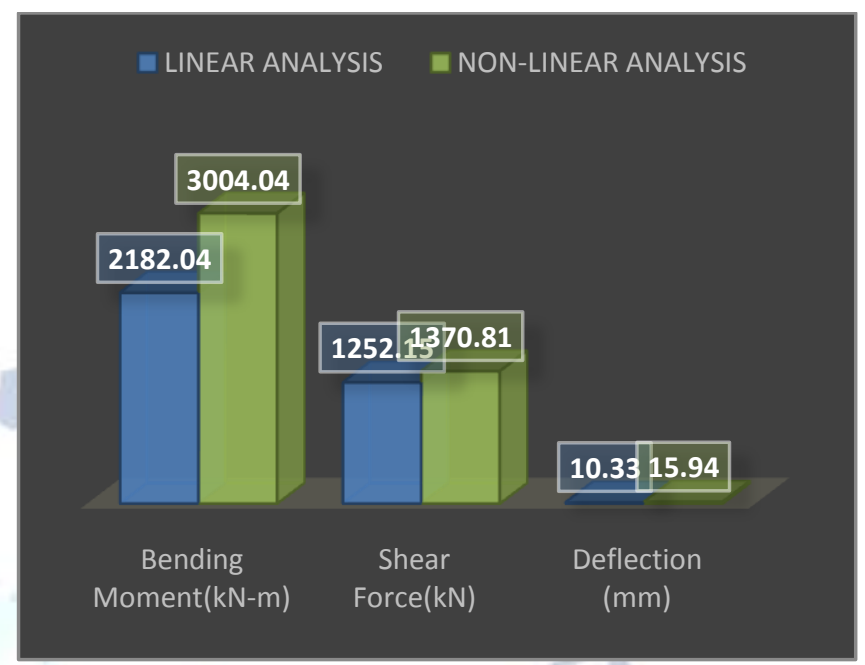

The following cases are considered in the structural analysis of berthing structure, they are:

Case 1: Linear static analysis.

Case 2: Nonlinear static analysis.

\section{V.RESULTS AND DISCUSSION}

After performing the linear and Nonlinear static analysis of structure is taken into consideration, their behavior is analyzed and compared in phrases of following parameters.

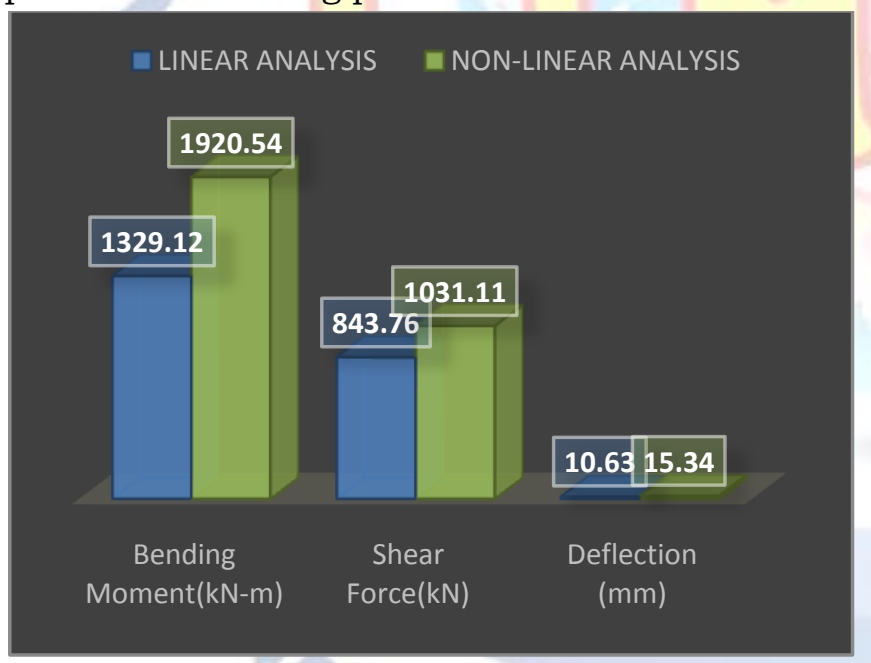

Fig-2:Comparison of Analysis Results of a Cross

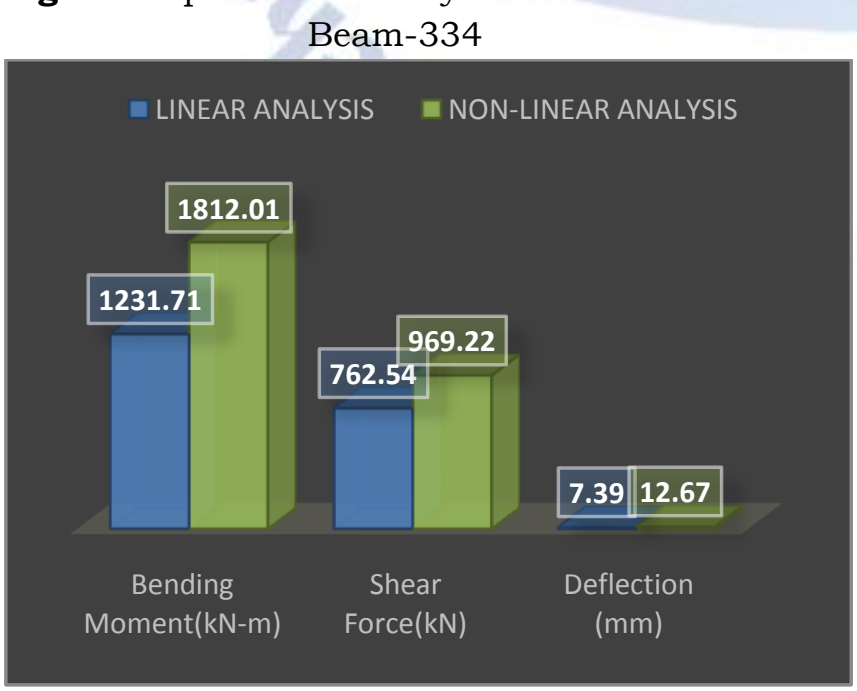

Fig-4:Comparison of Analysis Results of Front Crane Beam-428

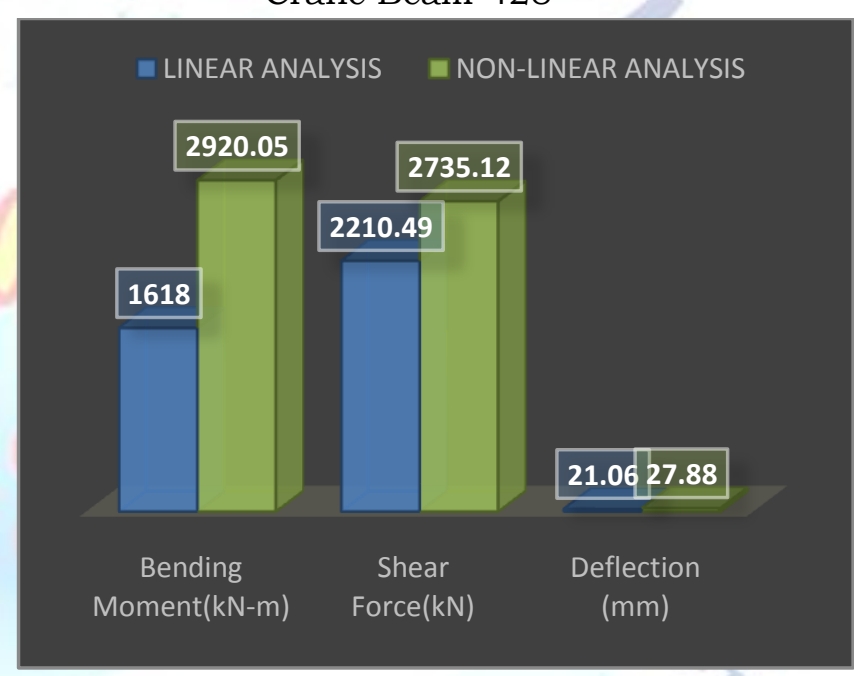

Fig-5:Comparison of Analysis Results of Retaining Beam-236

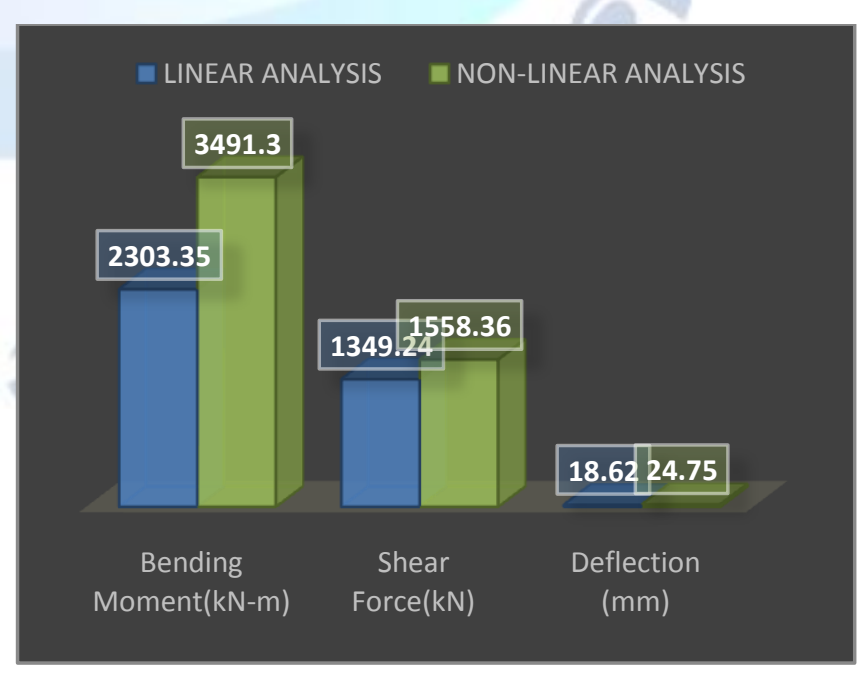

16 International Journal for Modern Trends in Science and Technology 


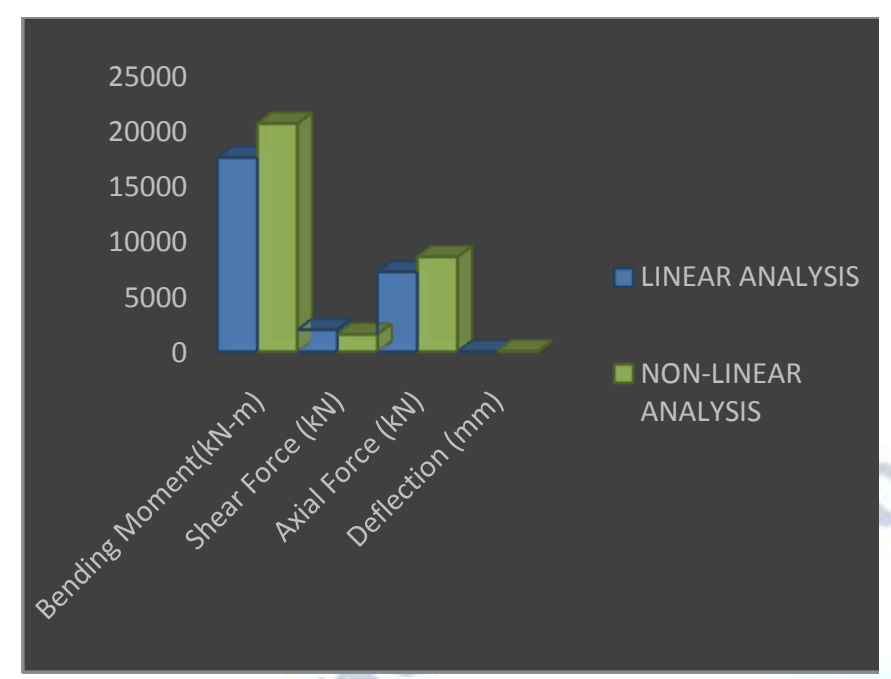

Fig-7:Comparison of Analysis Results of A-Row Pile-52

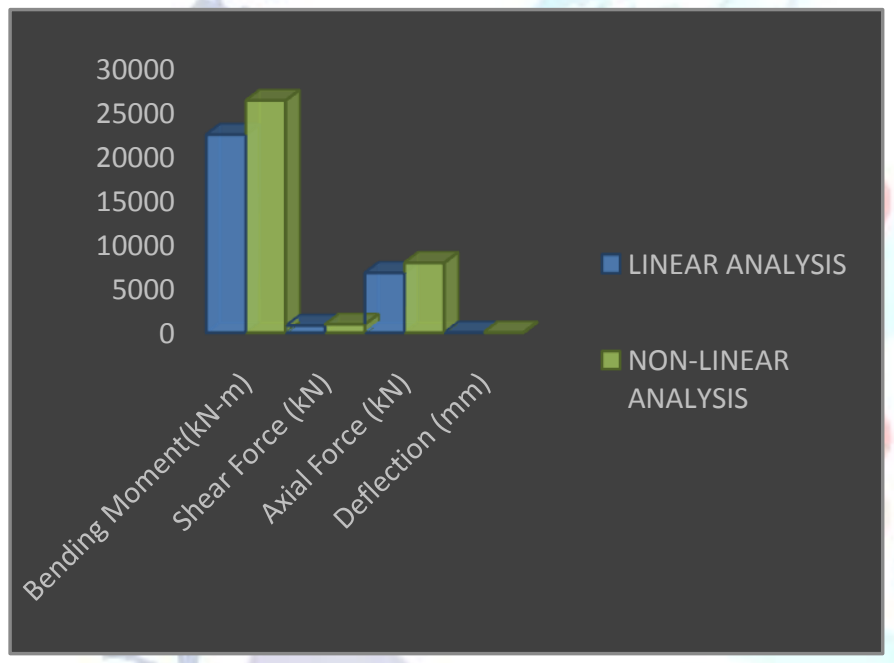

Fig-8: Comparison of Analysis Results of B Row Pile-398

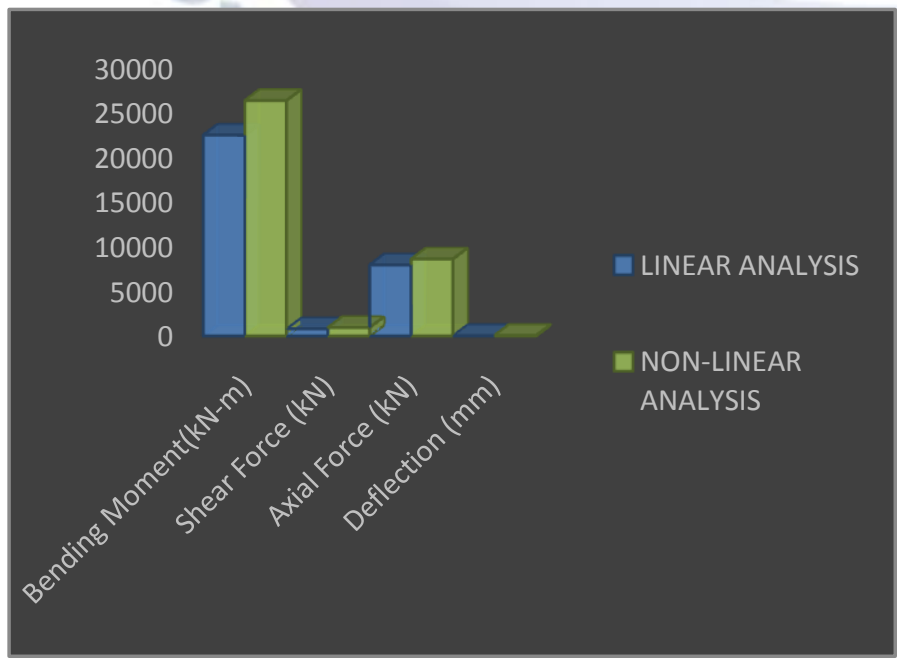

Fig-9: Comparison of Analysis Results of C Row Pile-397

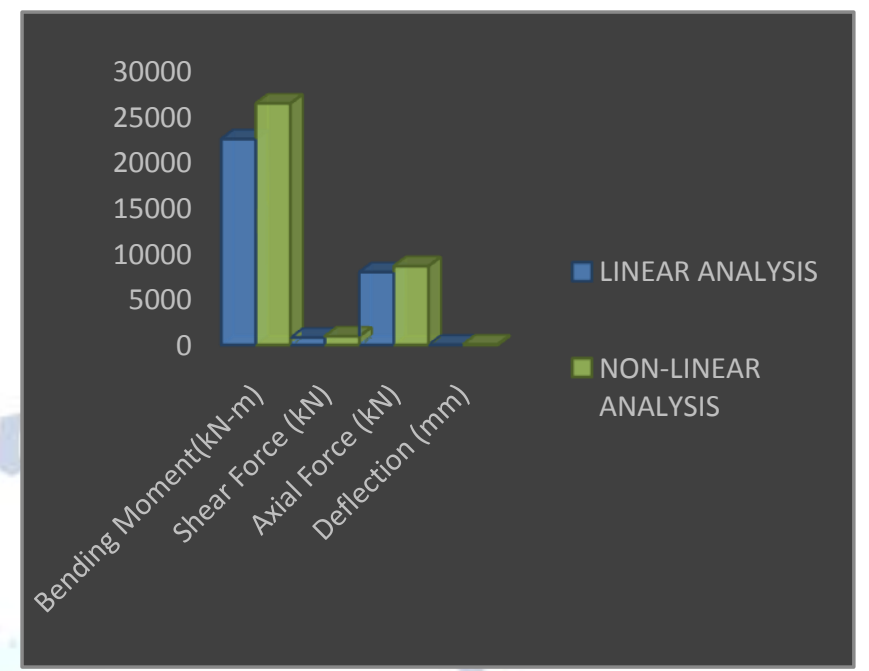

Fig-10:Comparison of Analysis Results of D-Row Pile-494

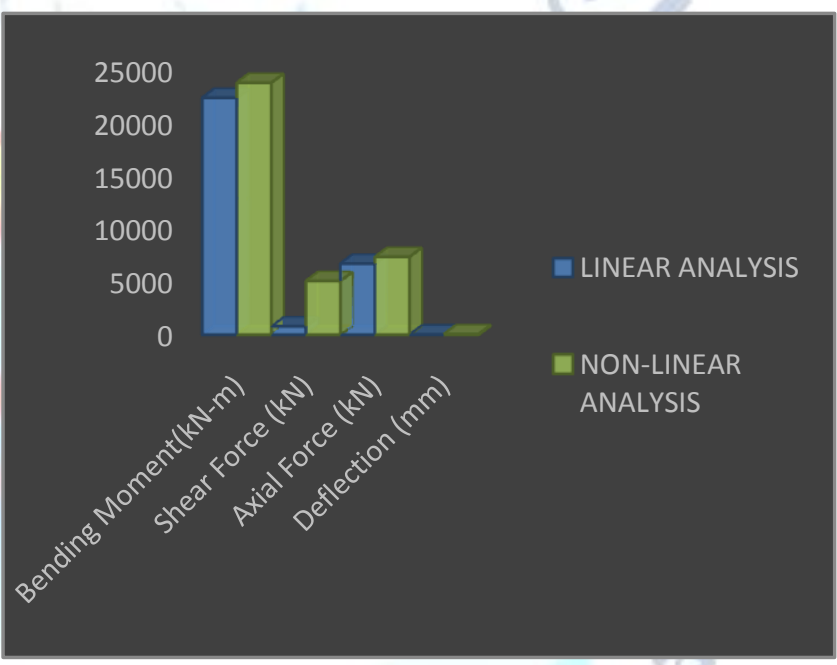

Fig-11:Comparison of Analysis Results of E-Row Pile-399

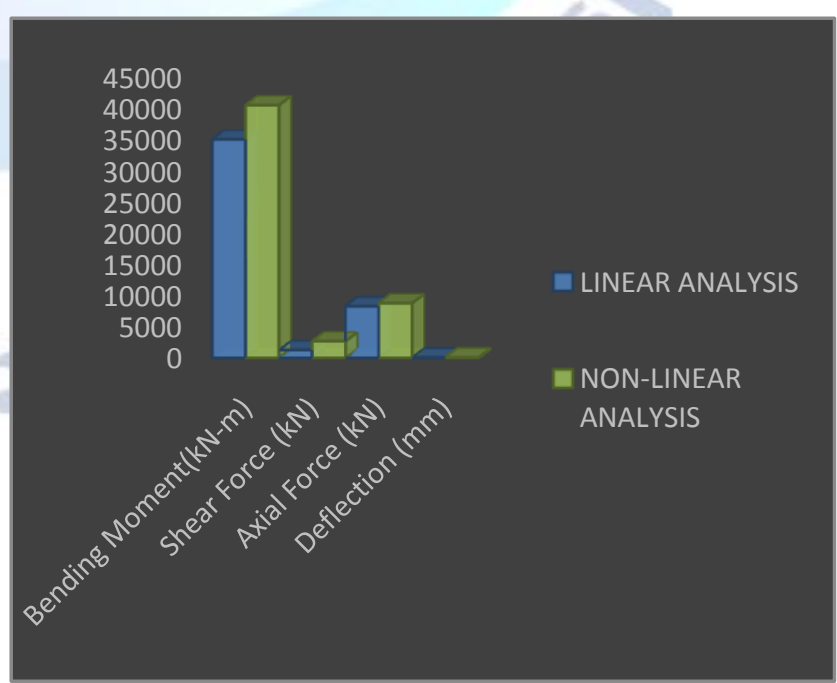

Fig-12:Comparison of Analysis Results of F-Row Pile-400 


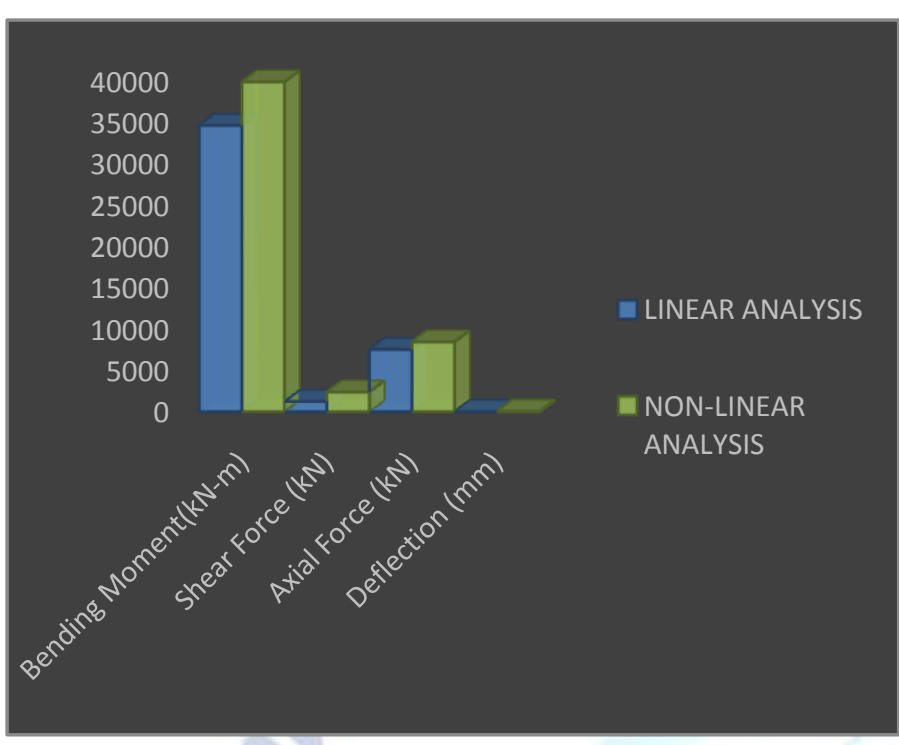

Fig-13: Comparison of Analysis Results of G-Row Pile-401

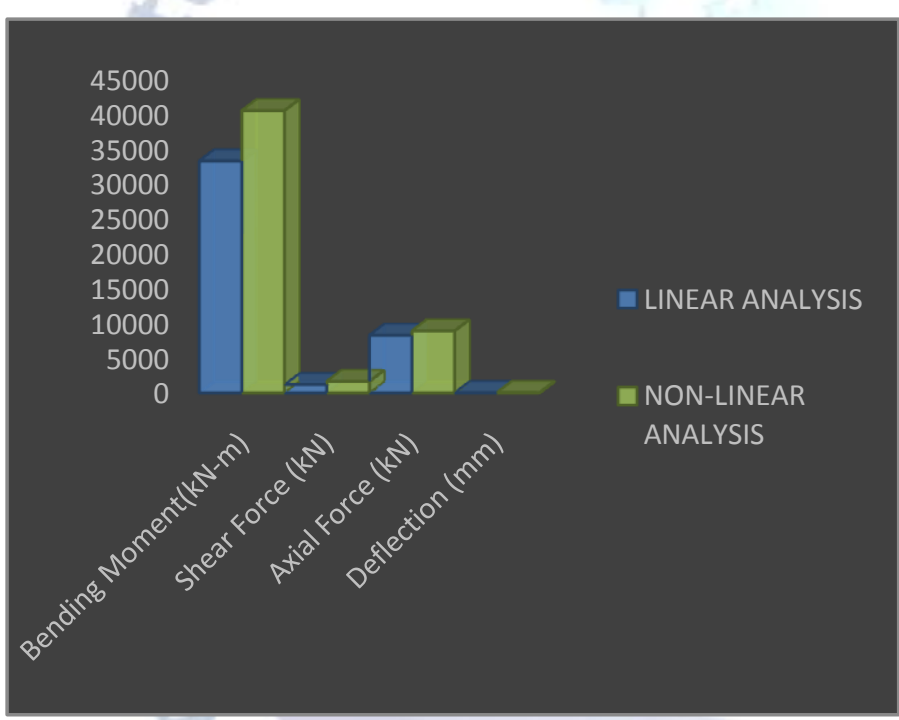

Fig-14:Comparison of Analysis Results of H-Row Pile-402

\section{VI.CONCLUSION}

From the comparison of linear and non-linear static analysis results the following conclusions were drawn.

- It is found that the variation of bending moment and displacement is more in dynamic analysis than in static analysis. Dynamic analysis is more critical and should be considered during the analysis of the structure.

- This proves that the design procedure carried out using Pushover method is more effective as it studies the real time behavior of the structure and brings efficiency in terms of cost too.

- It is found that the results of analysis of the berthing structure using STAAD Pro. software are very useful in the design of the structures as well as to undertake the performance analysis of the constructed structures.

- Pushover analysis is contemplated as an effective tool to assess the capability of structure for seismic forces and for this reason it is expected the actual behavior of the structure during earthquake.

\section{REFERENCES}

[1] A marine cargo berth design at Mumbai port trust by Kinjal Patel: [2018], Volume 5, Issue 4-(JETIR)-Page no-381-387.

[2] Seismic Analysis and Design of Cargo Berth by Ramesh Kannan-2017, Volume 8, Issue 6, June, pp. 411-422,

[3] Analysis and Design of Dock Berth Structure by B. Santosh Kumar: MARCH [2016], IJSART - Volume 2 Issue 3, Page no-8-16.

[4] Analysis and Design of Passenger Berthing Structure by Augustina- Feb -2017, Volume: 04 Issue: 02, pp. 67-77

[5] Analysis and Design of a Quay Berthing Structure by S. Nagarjuna- Aug 2018, Volume 4 Issue 4, July, pp.33-39.

[6] Finite Element Analysis of Berthing Structures by Anjana S Rao- April-2018, Volume 9, Issue 4, pp.199-124.

[7] Analysis and Design of Berthing Structure by Varuna Belagavi, July 2017, Volume 8, Issue 7, pp. 1111-1124.

[8] Study on the Structural behavior of Berthing Structure due to Variable Stack Load by G. T. Naidu- December 2016, Vol 9(45), ijst, pp. 1-6.

[9] An Approach on Optimization of Berth Structure at Port Sectors for Handling Bulk Cargo and Containers by Mr. Deekshith Shetty- July-2015, Vol. 4, Issue 07, (IJERT), pp.915-918.

[10] Application of Forces Acting on Jetty Structure by Himesh B. Chopra- May 2015, Volume 1, Issue 11, pp. 83-91.

[11] Structural System Evaluation of Jetties by M. RajkumarSeptember 2016, Volume 3, Issue 03, pp. 153-160.

[12] Reliability Based Analysis of Berthing Structure Subjected to Variable Crane Load by G. T. Naidu- Number 7 (2017), Volume 12, pp. 1123-1128.

[13] IS 1893 (Part 1): 2002 Indian Standard Criteria for Earthquake Resistant Design of Structures, Part 1 General Provisions and Buildings, (Fifth Revision).

[14] IS 875 (Part 2): 1987: Indian Standard Code of Practice for Design Loads (Other Than Earthquake) for Buildings and Structures, part 1 dead loads - unit weights of building materials and stored materials (Second Revision)

[15] IS 4651 (Part 3): 1974: Indian Standard Code of Practice for Planning and Design of Ports and Harbours Part Iii Loading (First Revision) 